\title{
Pregnancy Induced Hypertension and Associated Factors among Women Attending Delivery Service at Mizan-Tepi University Teaching Hospital, Tepi General Hospital and Gebretsadik Shawo Hospital, Southwest, Ethiopia
}

\author{
Tesfaye Abera Gudeta ${ }^{1}$, Tilahun Mekonnen Regassa ${ }^{2}$
}

\section{OPEN ACCESS}

Citation: Tesfaye Abera Gudeta' Tilahun Mekonnen Regassa. Pregnancy Induced Hypertension and Its Associated Factors among Women Attending Delivery Service at Mizan-Tepi University Teaching Hospital, Tepi and Gebretsadikshawo Hospitals, Southwest, Ethiopia. Ethiop J Health Sci. 2018; 29 (1):831.

doi:http://dx.doi.org/10.4314/ejhs.v29i1.4 Received: June 12, 2018

Accepted: June 13, 2018

Published: January 1, 2019

Copyright: (C) 2018 Tesfaye Abera, et al. This is an open access article distributed under the terms of the Creative Commons Attribution License, which permits unrestricted use, distribution, and reproduction in any medium, provided the original author and source are credited.

Funding: Bona District Health Bureau and Abem private clinic.

Competing Interests: The authors declare that this manuscript was approved by all authors in its form and that no competing interest exists. Affiliation and Correspondence: ${ }^{1}$ MizanTepi University, College of Health science, Department of Nursing, Maternal Health Nursing Unit

${ }^{2}$ MizanTepi University, College of Health Science, Department of Nursing, adult Health Hursing Unit *Email: tesfeabera2013@gmail.com

\begin{abstract}
BACKGROUND: Disorders of pregnancy induced hypertensive are a major health problem in the obstetric population as they are one of the leading causes of maternal and perinatal morbidity and mortality. The World Health Organization estimates that at least one woman dies every seven minutes from complications of hypertensive disorders of pregnancy. The objective of this study is to assess pregnancy induced hypertension and its associated factors among women attending delivery service at Mizan-Tepi University Teaching Hospital, Gebretsadikshawo Hospital and Tepi General Hospital.

METHODS: A health facility based cross-sectional study was carried out from October 01 to November 30/2016. The total sample size (422) was proportionally allocated to the three hospitals. Systematic sampling technique was used to select study participants. Variables with p-value of less than 0.25 in binary logistic regression were entered into the multivariable logistic regression to control cofounding. Odds ratio with $95 \%$ confidence interval was used. P-value less than 0.05 was considered as statistically significant.

RESULTS: The prevalence of pregnancy induced hypertension was 33(7.9\%); of which 5(15.2\%) were gestational hypertension, 12 (36.4\%) were mild preeclampsia, 15(45.5\%) were severe preeclampsia and 1 (3\%) eclampsia. Positive family history of pregnancy induced hypertension [AOR5.25 (1.39-19.86)], kidney diseases (AOR 3.32(1.04-10.58)), having asthma [AOR 37.95(1.411021)] and gestational age (AOR 0.096(0.04-.23)) were predictors of pregnancy induced hypertension.
\end{abstract}

CONCLUSION: The prevalence of pregnancy induced hypertension among women attending delivery service was $7.9 \%$.

Having family history of pregnancy induced hypertension, chronic kidney diseases and gestational age were predictors of pregnancy induced hypertension.

KEYWORDS: Pregnancy induced hypertension, associated factors, delivered women, $M T U$ 


\section{INTRODUCTION}

Hypertension in pregnancy is a systolic blood pressure $\geq 140 \mathrm{mmHg}$ or diastolic blood pressure $\geq 90 \mathrm{mmHg}$ or both. Both systolic and diastolic blood pressure raises are important in the identification of Pregnancy induced hypertension (1). Pregnancy induced hypertension (PIH) is hypertension that occurs after 20 weeks of gestation in women with previously normal blood pressure. The broad classification of pregnancyinduced hypertension during pregnancy is gestational hypertension, pre-eclampsia and eclampsia (2).

Severe preeclampsia in pregnancy is a systolic blood pressure $\geq 160 \mathrm{mmHg}$ or diastolic blood pressure $\geq 110 \mathrm{mmHg}$ or both. Eclampsia is a severe type of pregnancy induced hypertension, and it happens in about one in 1,600 pregnancies and develops near the end of pregnancy (4). The three primary characteristics of pregnancy induced hypertension conditions are high blood pressure, protein in the urine and pathologic edema (3-5).

Pregnancy induced hypertension is a major contributors to maternal and perinatal morbidity and mortality. In the United States, about $15 \%$ of maternal deaths are attributable to hypertension, making it the second leading cause of maternal mortality. Severe hypertension increases the mother's risk of cardiac failure, heart attack, renal failure and cerebral vascular accidents. In addition, the fetus is at increased risk from complications like poor placental transfer of oxygen, growth restriction, preterm birth, placental abruption, stillbirth and neonatal death (2). Hypertensive disorders represent the most common medical complications of pregnancy with a reported incidence of $5-10 \%(6,7)$.

Globally, preeclampsia is a leading cause of maternal and neonatal mortality and morbidity, predominantly in developing countries. The disorder is usually diagnosed in late pregnancy by the presence of high blood pressure with proteinuria and/or edema. Prevention of any disease process needs awareness of its prevalence, etiology and pathogenesis (8). The World Health Organization estimates that at least one woman dies every seven minutes from complications of pregnancy induced hypertension disorders. Pregnancy complicated with hypertensive disorder is related with increased risk of adverse fetal, neonatal and maternal outcome (9).

Null parity, multiple pregnancies, history of chronic hypertension, gestational diabetes, fetal malformation, obesity, extreme maternal age (less than 20 or over 40 years), history of PIH in previous pregnancies and chronic diseases like renal disease, diabetes mellitus, cardiac disease, unrecognized chronic hypertension, positive family history of PIH which shows genetic susceptibility, psychological stress, alcohol use, rheumatic arthritis, extreme underweight and overweight, asthma and low level of socioeconomic status are the risk factors for PIH $(5,10,11)$. According to a study in South Africa, the incidence of hypertensive disorders of pregnancy was $12 \%$, and it was the commonest cause of maternal death which contributed $20.7 \%$ of maternal deaths (12).

As the Ethiopian Demographic Health survey (EDHS) 2016 reported, maternal mortality ratio is 412 deaths per 100,000 live births, and pregnancy induced hypertension has a countless role for this maternal death (13). A review study conducted on the causes of maternal mortality in Ethiopia indicated that the proportion of maternal mortality in Ethiopia due to hypertensive disorders between the year of 1980 and 2012 was in an increased trend from 4\%-29\% (14).

The Federal Ministry of Health has applied multi-pronged approaches to reducing maternal and newborn morbidity and mortality by improving access to and strengthening facilitybased maternal and newborn services but the maternal morbidity and mortality due to pregnancy induced hypertension was in an increasing trend (15).

Despite the fact that pregnancy induced hypertension is a leading causes of maternal morbidity and mortality during pregnancy, little is known about the current magnitude of PIH, its associated factors among women attending delivery service in Ethiopia and specifically in study areas. Therefore, the objective of this study was to assess pregnancy induced hypertension and its associated factors among women attending

DOI: http://dx.doi.org/10.4314/ejhs.v29i1.4 
delivery service at Mizan Tepi University Teaching Hospital, Gebretsadikshawo Hospital and Tepi General Hospital, Southwest Ethiopia.

\section{MATERIALS AND METHODS}

Study area and period: The study was conducted in Mizan Tepi University Teaching Hospital, Tepi General Hospital and Gebretsadikshawo Hospital found in Benchi Maji, Sheka and Kefa zones from October 01November 30/2016. Mizan Tepi University Teaching Hospital is located in Bench Maji Zone $560 \mathrm{kms}$ far from Addis Ababa, and Gebretsadikshawo is found $441 \mathrm{kms}$ from Addis Ababa in Kefa Zone and Tepi General Hospital is located in Sheka Zone $565 \mathrm{kms}$ from the capital city of Ethiopia, Addis Ababa.

Study design: Health facility based crosssectional study design with quantitative data collection method was used.

Source and study population: All women who attended delivery service in Mizan Tepi University teaching Hospital, Tepi General Hospital and Gebretsadikshawo Hospital were considered as source population whereas all sampled women were considered as study population.

Inclusion and exclusion criteria: All admitted women in delivery ward with gestational age greater than 28 weeks were included to the study whereas women with known chronic hypertension and those who were critically ill and unable to communicate after full course of treatment were excluded from the study. A woman who was critically ill due to PIH was waited until she recovered from her illness.

Sample size and sampling technique: The sample size was calculated by using a single population proportion sample size calculation formula by considering the following assumptions: $d=$ margin of error of $5 \%$ with $95 \%$ confidence interval and $\mathrm{P}=50 \%$ in order to maximized the sample size. By considering $10 \%$ none response rate, the final sample size became 422.

The total sample size was proportionally allocated to the three public hospitals based on their source population from each hospital. The source population of each hospital was taken from six-month delivery reports. Then, the average was considered as source population (1030). Afterwards, the study participants were systematically selected from each hospital, and admitted mothers for delivery who were eligible to the study were included until the required sample size was obtained (Figure 1).

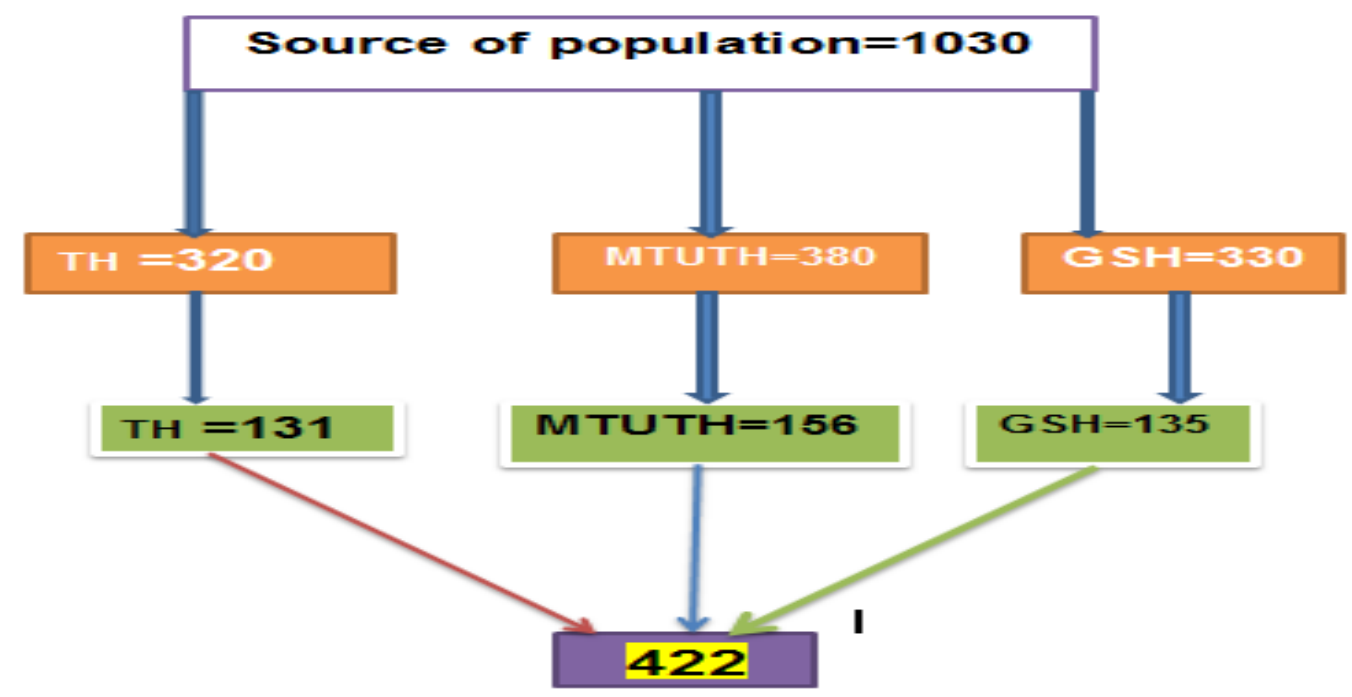

Figure 1: Schematic presentation of sampling procedure

DOI: http://dx.doi.org/10.4314/ejhs.v29i1.4 
Pregnancy induced hypertension (PIH): A pregnant women attending delivery service with high blood pressure $(\geq 140 / 90 \mathrm{mmHg})$ after 28 weeks of gestation was measured two times six hours apart by trained data collectors and with or without proteinuria. The diagnosis of PIH was confirmed by a physician working in labour ward. Pregnancy induced hypertension includes gestational hypertension, pre-eclampsia and eclampsia.

Psychological stress: A woman who scored greater than the mean score was considered as psychologically stressed.

Data collection instruments: The data was collected by using pre-tested structured questionnaire adapted from a validated questionnaire $(16,17)$. The questionnaire was first adapted in English and translate into Amharic by an expert and translated back to English to see the consistency of the item. The questionnaire contains sections for assessing demographics and associated factors. The questions and statements were grouped and arranged according to the particular objectives that they were aimed to address. Six data collectors who were degreeholding midwives in qualification fluent in speaking, writing and reading Amharic language were recruited purposefully from their respective facilities to maintain the quality of the data. also Three supervisors were recruited for the same purpose.

Data collection procedure: Data was collected through face-to-face interview, measurements and reviewing of medical records of the mother using pretested structured questionnaire by trained data collectors. Data were collected day and night in order not to miss the cases. Blood pressure reading was taken while the woman was seated in the upright position and supine position using a mercury sphygmomanometer apparatus, and for referred women, BP and protein urea at time of diagnosis were taken from referral form.

Data processing and analysis: EPI data statistical software version 3.1 and Statistical Package for Social Sciences (SPSS) software version 21.0 were used for data entry and analysis. After organizing and cleaning the data, frequencies and percentages were calculated to all variables that were related to the objectives of the study. Variables with p-value less than 0.25 in binary logistic regression analysis were entered into the multivariable logistic regression analysis to control confounders. Odds ratio with $95 \%$ confidence interval was used to examine associations between dependent and independent variables. P-value less than 0.05 was considered significant. Finally, the result was presented by using tables and narrative forms.

Data quality control measures: The quality of the data was assured by using validated and pretested questionnaire. Prior to the actual data collection, pre-testing was done on $5 \%$ of the total study subjects at Chena Hospital which was not included in the actual study, and based on the findings necessary amendments were made. Reliability of the questions used to measure psychological stress of mothers was tested by Cronbach's alpha test (0.89). Data collectors were trained for one day intensively on the study instrument and data collection procedure that included the relevance of the study, the objective of the study, confidentiality of the information, informed consent and interview technique. The data collectors worked under close supervision of the supervisors to ensure adherence to correct data collection procedures. The supervisors reviewed the filled questionnaires at the end of data collection every day for completeness.

Every morning, the supervisors and the data collectors conducted a morning session to solve problem, if encountered, as early as possible and to take corrective measures accordingly. Moreover, the data was carefully entered and cleaned before the analysis.

Ethical considerations: The study did not involve any experiment, and no harm was expected on human subjects, exception of benefit. Ethical clearance from Mizan Tepi University and permission from respective authorities and written consent of respondents' were obtained before the data collection. To get full co-operation, respondents were reassured about the confidentiality of their responses. They were also informed their voluntarily participation and right to take part or terminate at any time they wanted.

DOI: http://dx.doi.org/10.4314/ejhs.v29i1.4 
Since the subjects of the study could raise ethical issues, care was taken in the design of the questionnaire.

\section{RESULTS}

Socio-demographic characteristics: Among the total study participants, $155(37.3 \%)$ were aged between 20-24 years, more than half 236(56.7\%)of the respondents were orthodox in religion, and $403(96.9 \%)$ were married. Almost half of the participants were from rural areas, 214(51.4\%). Regarding their educational level, 150(36.1\%) of the respondents attended primary school, the majority $276(66.3 \%)$ were housewives, and 230(55.3) of the family sizes of the participants were between 3-4 (Table 1).
Prevalence of pregnancy induced hypertension: The prevalence of pregnancy induced hypertension among women attending delivery service in the three hospitals of this study was $33(7.9 \%)$. The mean of systolic blood pressure was $110.72 \pm 15.315$ with range of $90 \mathrm{mmHg}$ to $210 \mathrm{mmHg}$, and the mean of diastolic blood pressure was $72.71 \pm 13.093$ with range of $50 \mathrm{mmHg}$ to $160 \mathrm{mmHg}$. The result of proteinuria ranged from negative to $3+$ in dipstick test. Out of the total of women who had pregnancy induced hypertension, 5(15.2\%) were gestational hypertension, $12(36.4 \%)$ were mild preeclampsia, $15(45.5 \%)$ were severe preeclampsia and 1(3\%) were eclampsia.

Table 1: Distribution of the study participants by their socio- demographic characteristics at MTUTH, Tepi and Gebretsadikshawo hospitals, south west Ethiopia, Nov, 2016.

\begin{tabular}{llcc}
\hline \multicolumn{1}{c}{ Variables } & & Frequency(n=416) & percent \\
\hline Age of women & $<20$ & 54 & 13.0 \\
& $20-24$ & 155 & 37.3 \\
& $25-29$ & 131 & 31.5 \\
Address of women & $30-34$ & 45 & 10.8 \\
& $\geq 35$ & 31 & 7.5 \\
Religion & Rural & 214 & 51.4 \\
& Urban & 202 & 48.6 \\
& Muslim & 57 & 13.7 \\
& Orthodox & 236 & 56.7 \\
Marital status & Protestant & 118 & 28.4 \\
& Catholic & 1 & 0.2 \\
& Other* & 4 & 1.0 \\
& Married & 403 & 96.9 \\
Educational status & Single & 10 & 2.4 \\
& Divorced & 2 & 0.5 \\
& Widowed & 1 & 0.2 \\
& Illiterate & 104 & 25.0 \\
& Primary & 151 & 36.3 \\
& Secondary school & 78 & 18.8 \\
& Preparatory school & 26 & 6.2 \\
& Diploma & 47 & 11.3 \\
Oamily size & Degree and above & 10 & 2.4 \\
& Housewife & 277 & 66.6 \\
& Governmental & 69 & 16.6 \\
& NGO & 53 & 12.7 \\
& Self & 17 & 4.1 \\
& $1-2$ & 83 & 20.0 \\
& $3-4$ & 230 & 55.3 \\
& $\geq 5$ & 103 & 24.8 \\
\hline \multirow{5}{*}{ Occupational status } & & &
\end{tabular}

*Other -neutral

DOI: http://dx.doi.org/10.4314/ejhs.v29i1.4 
Variables related to obstetric conditions: Out of the pregnant women who participated in study, $408(98.1 \%)$ of the pregnancy were wanted, and $224(53.8 \%)$ of pregnancy were multigravida. Regarding parity of the women, $261(62.7 \%)$ had parity of $1-4$, and the majority, $309(74.3 \%)$ of gestational ages were between 37 and 42 weeks. Only $5(1.3 \%)$ of the pregnant mothers who were admitted for delivery had previous history of PIH, only $3(0.8)$ of them had history of gestational diabetic mellitus while $20(4.8 \%)$ of the pregnancies were multiple ones (Table 2).

Table 2: Frequency distribution of variables related to obstetric conditions among women attending delivery service at MTUTH, Tepi and Gebretsadikshawo hospitals, southwest Ethiopia, 2016

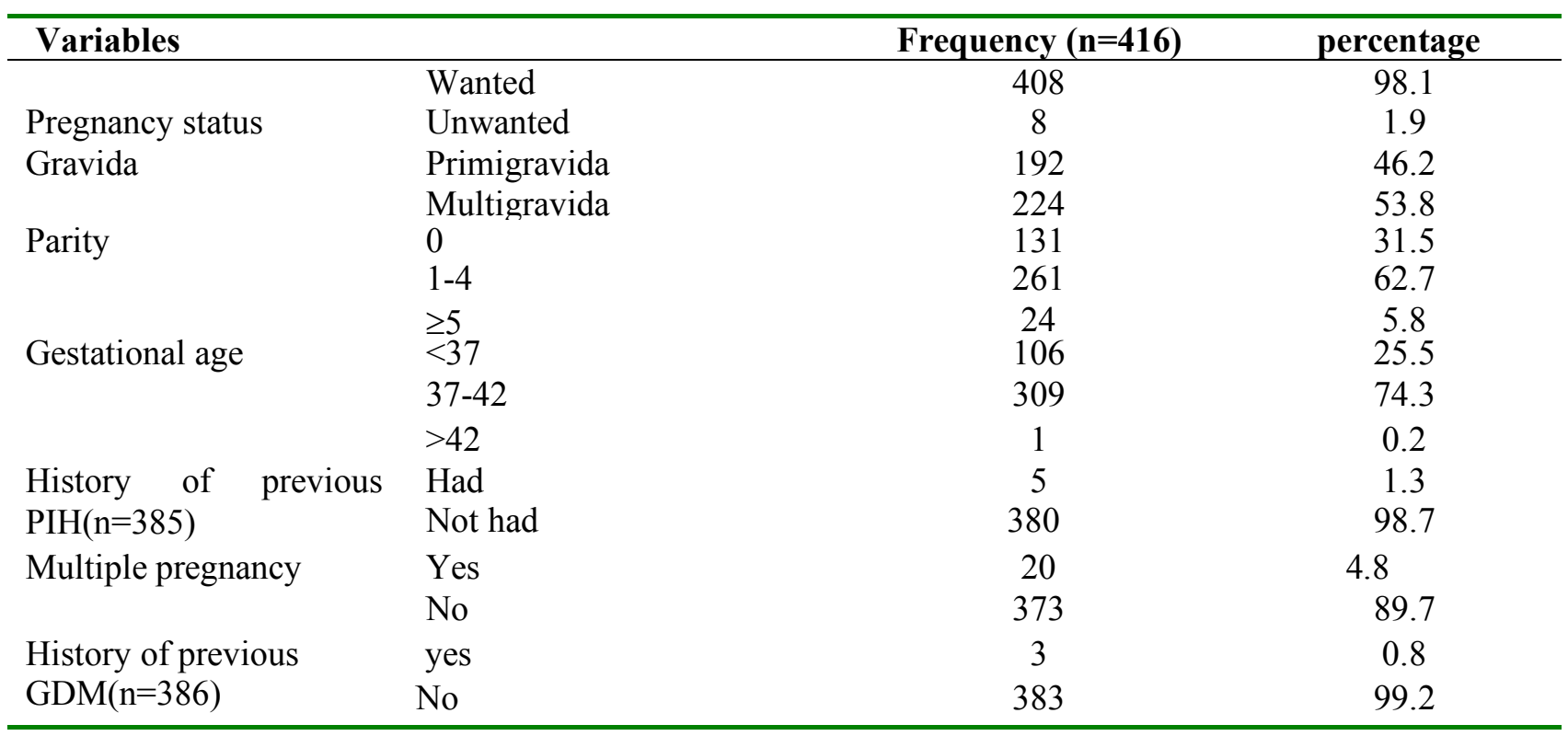

NB: GDM=Gestational Diabetic Mellitus

Medical and family history related variables: Regarding medical and family histories of illness, out of the total, $43(10.3 \%)$ had family history of chronic hypertension, $16(3.8 \%)$ of them had family history of pregnancy induced hypertension commonly from their mothers, 11(84.6). Regarding kidney diseases, $32(7.7 \%)$ of the respondents had history of kidney diseases during the current pregnancy, and only $7(1.7 \%)$ of them had history of chronic diabetic mellitus. From the study participants, only $36(8.7 \%)$ of them had family history of diabetic mellitus and $2(0.5 \%)$ of them had history of asthma (Table 3 ).

DOI: http://dx.doi.org/10.4314/ejhs.v29i1.4 
Table 3: Distributions of medical and family history risk factors among delivered women at MTUTH, Tepi and Gebretsadikshawo hospitals, South west Ethiopia, 2016

\begin{tabular}{llcc}
\hline Variables & & Frequency $=\mathbf{4 1 6}$ & Percent \\
\hline Family history of chronic hypertension & Had & 43 & 10.3 \\
Family history of PIH & Not had & 373 & 89.7 \\
& Had & 16 & 3.8 \\
History of diabetic mellitus(DM) & Not had & 402 & 96.6 \\
& Had & 7 & 1.7 \\
Family history of DM & Not had & 409 & 98.3 \\
& Had & 36 & 8.7 \\
History of kidney diseases & Not had & 380 & 91.3 \\
& Had & 32 & 7.7 \\
Currently history of asthma. & Not had & 389 & 93.5 \\
& Had & 2 & 0.5 \\
\hline
\end{tabular}

Variables related to personal risks: Among the respondents, $9(2.2 \%)$ had history of smoking cigarette, of which $2(0.5 \%)$ were current smokers while $23(5.5 \%)$ of the family members smoked cigarette, mostly the husbands, 20 (87\%). From the total of the mothers attending delivery service, $350(84.1 \%)$ had mid upper arm circumference $\geq 21 \mathrm{~cm}$ whereas $66(15.9 \%)$ them were $<21 \mathrm{~cm}$.
Regarding sleeping pattern of women during current pregnancy, more than half, 250(60.1\%), of them sleep $\geq 9$ hours per night, and 164(39.4\%) of women were doing scheduled regular physical exercise during their current pregnancy. Based on the nine items used to assess psychological stress, $171(41.1 \%)$ of the women had psychological stress during current pregnancy (Table 4).

Table 4: Distribution of the study subjects by their personal risk factors among women attending delivery service at MTUTH, Tepi and Gebretsadikshawo hospitals, Southwest Ethiopia, Nov, 2016.

\begin{tabular}{llll}
\hline Variables & & Frequency & Percent \\
\hline Any cigarettes smoking & No & 407 & 97.8 \\
& Yes & 9 & 2.2 \\
Status of smoking & Current smoker & 2 & 0.5 \\
& Former smoker & 7 & 1.7 \\
Any family members who smoke cigarette & Yes & 23 & 5.5 \\
& No & 393 & 94.5 \\
Whom family members smoke cigarette(n=23) & Husband & 20 & 87.0 \\
& Other* & 3 & 13.0 \\
Psychological stress during current pregnancy & Not stressed & 245 & 58.9 \\
(n=416) & Stressed & 171 & 41.1 \\
Mid upper arm circumference in centimeter & $<21 \mathrm{~cm}$ & 66 & 15.9 \\
(n=416) & $\geq 21 \mathrm{~cm}$ & 350 & 84.1 \\
Sleep pattern in hours per night(n=416) & $\leq 6$ & 13 & 3.1 \\
& $7-8$ & 153 & 36.8 \\
Mothers took nap per day (n=416) & $\geq 9$ & 250 & 60.1 \\
& Yes & 233 & 56.0 \\
Perform scheduled physical exercise during & Yes & 183 & 44.0 \\
current pregnancy (n=416) & No & 164 & 39.4 \\
\hline Nhing & No & 252 & 60.6 \\
\hline
\end{tabular}

*Children, Relatives, Any other person live with family members

DOI: http://dx.doi.org/10.4314/ejhs.v29i1.4 
Variables related to health facility utilization: According to this study, 406(97.6\%) of the pregnant mothers utilized health facility for ANC follow-up, of which $8(2 \%)$ attended first visit of their routine ANC follow-up and 398 (98\%) attended ANC more than twice. Regarding utilization of health facilities for health problems other than the current pregnancy, only $132(31.7 \%)$ utilized health facilities for gynecology, surgical and medical problems.

Predictors of pregnancy induced hypertension: In the multivariable logistic regression analysis, factors contributing to pregnancy induced hypertension were identified: Positive family history of pregnancy induced hypertension, kidney diseases during pregnancy, asthma and gestational age had statistically significant associations with pregnancy induced hypertension (Table 5).

The pregnant women attending delivery service with family history of pregnancy induced hypertension were five times more likely to develop pregnancy induced hypertension than those who did not have family history of pregnancy induced hypertension ( $\mathrm{AOR}=5.25$ at $95 \% \mathrm{CI}=(1.39-19.86)$.

As this study showed, having kidney diseases during pregnancy was 3.25 times more likely to develop pregnancy induced hypertension as compared to pregnant mothers who did not have kidney diseases during pregnancy $(\mathrm{AOR}=3.32$ at $95 \% \mathrm{CI}=(1.04-10.58)$. Women who had asthma more likely develop pregnancy induced hypertension by 38 times as compared with women those attending delivery service did not have asthma (at 95\% CI, AOR=37.95(1.411021).

In this study, gestational was age identified as predictor, indicating that women with gestational age greater than or equal to 37 weeks were less likely to develop pregnancy induced hypertension by $9.6 \%$ as compared to women gestational age less than 37 weeks $(\mathrm{AOR}=0.096$ at $95 \% \mathrm{CI}(0.04-0.23)$ (Table 5).

Table 5: Multivariable logistic regression analysis of pregnancy induced hypertension and associated factors among women attending delivery service at MTUTH, Tepi and Gebretsadikshawo hospital, Southwestern 11 Ethiopia, 2016.

\begin{tabular}{llll}
\hline Variables & & COR (95\% CI) & AOR(95\%CI \\
Family size & $1-2$ & $\mathbf{1 . 0 0}$ & $\mathbf{1 . 0 0}$ \\
& $3-4$ & $1.82(0.67-4.93)$ & $1.44(0.47-4.40)$ \\
Gestational age & $\geq 5$ & $0.71(0.22-2.85)$ & $0.59(0.13-2.67)$ \\
& $<37$ & $\mathbf{1 . 0 0}$ & $\mathbf{1 . 0 0}$ \\
Gravida & $\geq 37$ & $0.12(0.06-.26)$ & $\mathbf{0 . 0 9 6 ( \mathbf { 0 . 0 4 } - 0 . 2 3 ) * *}$ \\
& Primigravida & $1.53(0.76-3.10)$ & $1.17(0.48-2.86)$ \\
Family history of PIH & Multigravida & $\mathbf{1 . 0 0}$ & $\mathbf{1 . 0 0}$ \\
& Yes & $6.04(1.96-18.60)$ & $\mathbf{5 . 2 5}(\mathbf{1 . 3 9 - 1 9 . 8 6})^{*}$ \\
Kidney diseases & No & $\mathbf{1 . 0 0 0}$ & $\mathbf{1 . 0 0}$ \\
& Yes & $3.05(-1.16-8.05)$ & $\mathbf{3 . 3 2 ( 1 . 0 4 - 1 0 . 5 8 ) *}$ \\
Asthma & No & $\mathbf{1 . 0 0}$ & $\mathbf{1 . 0 0}$ \\
& Yes & $11.94(0.729-195.36)$ & $\mathbf{3 7 . 9 5 ( 1 . 4 1 - 1 0 2 1}) *$ \\
MUAC measurement & No & $\mathbf{1 . 0 0}$ & $\mathbf{1 . 0 0}$ \\
& $<21 \mathrm{~cm}$ & $\mathbf{1 . 0 0}$ & $\mathbf{1 . 0 0}$ \\
& $\geq 21 \mathrm{~cm}$ & $0.558 \quad(0.24-1.30)$ & $0.51(0.19-1.35)$ \\
\hline
\end{tabular}

*Statistically Significant $(\mathrm{P}<0.05), \quad * *$ high statistically significant $(\mathrm{p}<0.01)$

\section{DISCUSSION}

The prevalence of pregnancy induced hypertension among women attending delivery service in this study was $33(7.9 \%)$. This might increase the morbidity and mortality of the mother and the fetus. If appropriate preventive measures are not taken for the risk of pregnant women, in long term, it might be the first cause of maternal mortality. The prevalence of PIH in this study is similar with the study conducted in India which was $7.8 \%$ ( 18). However, it is slightly lower than the findings of studies done in Iran 9.8\% (19), in Jimma University Specialized Hospital (8.48\%) and Dessie Referal Hospital, 8.4\%(20,21).

This difference might be attributed to differences in the study period and study design. The population might also be different in lifestyle and culture. However, the

DOI: http://dx.doi.org/10.4314/ejhs.v29i1.4 
prevalence in this study is still greater than the study done in Ethiopia at Tikur Anbessa Hospital which was 5.3\% and Mettu Karl Hospital, 2.4\% (7, 22).

This discrepancy might be because of differences in the study period, study design and health seeking behaviors of pregnant women. In addition, the gap might be due to current health policy which focuses on implementation of focused ANC and exempted service for maternal care which increases the health care seeking behavior of pregnant women and delivery at health facility which increases detection of the case.

In this study, some associated factors of pregnancy induced hypertension were also identified. Having family history of pregnancy induced hypertension had about five times greater odds of developing pregnancy induced hypertension. This is consistent with the study conducted in Ghana (23) and in the textbook of current diagnosis and treatment in obstetrics and gynecology (2). This might have occurred due to genetic factors that contribute to the physiologic predisposition of pregnancy induced hypertension.

This study revealed that having kidney diseases during pregnancy increases the likelyhood of pregnancy induced hypertension.This finding was similar with the study conducted in Public Health facility of Dirashe Woreda which showed that preexisting renal diseases had statistically significant associations with pregnancy induced hypertension (24). Other theories also support that renal physiological function had direct relationship with cardiovascular system (2).

This study also showed that women who had asthma are at more risk to develop pregnancy induced hypertension than those who did not have asthma. This is in line with the study conducted in New York and Canada $(25,26)$. The other variable associated with $\mathrm{PIH}$ in this study was gestational age, which showed that women with gestational age greater than or equal to 37 weeks were less likely to develop pregnancy induced hypertension than women with gestational age less than 37 weeks. However this is inconsistent with the literature. This might be due to the fact that the population of this study was women attending delivery service so that more women with PIH might be delivered before and around 37 weeks of gestational age to reduce the risk of maternal and fetal complication.

As any other cross-sectional study, this study has strength and weakness. The possible limitations may arise from women's readiness and ability to provide every information about themselves and their family correctly based on which $\mathrm{PIH}$ was related and; recall and social desirability bias may be introduced during data collection from the pregnant women as they were self-referred. However, measure has been taken to minimize these limitations by using targeted questions.

The other limitation of this study was few variables have small observation which causes lower precision, so it was carefully interpreted. Inclusion of all hospitals from the three zones was strength of this study.

The prevalence of pregnancy induced hypertension among women attending delivery service was $7.9 \%$ which indicates that a significant number of women attending delivery services at Mizan Tepi Teaching Hospital, Gebretsadikshawo and Tepi Hospital developed pregnancy induced hypertension. Among pregnancy induced hypertensions, severe preeclampsia was the most common. Having family history of pregnancy induced hypertension, chronic renal diseases (kidney diseases) and gestational age were the factors associated with pregnancy induced hypertension.

\section{ACKNOWLEDGMENT}

We are extremely grateful to the Mizan Tepi University for grant fund, study subjects involved in the study, data collectors and supervisors.

\section{REFERENCES}

1. Kacica M, Dennison B, Aubrey R. Hypertensive Disorders in Pregnancy guideline summary. New York State Department of Health 2013 https://www.health.ny.gov/professionals/protocols.

2. Paola Aghajanian P, Ainbinder S, Andrew E. Vicki VB, Heather B, Helene B et al. Current Diagnosis and Treatment in Obstetrics and Gynecology, the McGraw-Hill., 2006.

3. Menzies J,Magee LA, Li J.Instituting surveillance guidelines and adverse outcomes in preeclampsia. Obstet Gynecol, 2007; 110:121-7.

4. Parmar MT, Solanki HM, Gosalia VV. Study of Risk Factors of Perinatal Death in Pregnancy Induced Hypertension (PIH). Natl J Community Med. 2012; 3(4).

5. Charles, Aline M. Maternal blood lead levels and the risk of pregnancy-induced hypertension. The EDEN Cohort Study. Environmental Health Perspectives 117.10 (2009): 1526+.

6. Prakash J, Pandey LK, Singh AK, and Kar B. Hypertension in pregnancy: Hospital based study. $J$ Associan physicians of India. 2006; 54:273278.

DOI: http://dx.doi.org/10.4314/ejhs.v29i1.4 
7. Teklu S and Gaym A: Prevalence and clinical correlates of the hypertensive disorders of pregnancy, Ethiop Med J. 2006 Jan; 44(1):17-26.

8. Ojodun $\mathrm{O}$ : The prevalence of hypertensive complications of pregnancy in Dora hospital,PortElizabeth,EasternCape,http://scholar. sun.ac.za/bitstream/handle/10019.1/20451 accessed on $01 / 12 / 2015 /$.

9. Dadelszen $P$ and Magee L. What matters in preeclampsia are the associated adverse outcomes? The view from Canada, Current opinion in obstetrics and Gynaecology 2008; 20:110-15.

10. Dolea $\mathrm{C}$ and AbouZahr C. Global burden of hypertensive disorders of pregnancy in the year 2000, Evidence and Information for Policy (EIP), World Health Organization. Geneva, and July 2003 / accessed on 01/12/2015/.

11. Parveen N, Haider G, Shaikh IA, Ujjan ID. Presentation of Predisposing Factors of Pregnancy Induced Hypertension at Isra University Hospital, Hyderabad, and Jlumhs September-December 2009; Vol: 08 No. 03.

12. Moodey J. Maternal death associated with hypertensive disorders of pregnancy: A population based study. Hypertension in pregnancy. 2005; 23:247-256.

13. Central Statistical Agency (CSA) [Ethiopia] and ICF. 2016. Ethiopia Demographic and Health Survey 2016: Key Indicators Report. Addis Ababa,Ethiopia, and Rockville, Maryland, USA.CSA and ICF.

14. Berhan $\mathrm{Y}$ and Berhan A. cause of maternal mortality in Ethiopia, Ethiopian journals of health Sciences, 2014, ISSN 1029-1857, 15.

15. Federal Democratic Republic of Ethiopia Ministry of Health. Health Sector Development Program IV 2010/11 - 2014/15.

16. David Kilembe F. Hypertensive disorders of pregnancy: Prevalence, Maternal Complications and Perinatal Outcomes at Lilongwe Central Hospital, Malawi, 2008, https://www.duo.uio.no/handle/10852/223/ accessed on $06 / 12 / 2014 /$.

17. CDC: Pregnancy Risk Assessment Monitoring System, Phase 6 Core Questionnaire, Jan. 28,
2009. www.cdc.gov/PRAM (accessed on 09/12/2014).

18. Sajith M, Vandana NV, Modi A, and Sumariya R, Pawar A. Incidence of pregnancy induced hypertension and prescription pattern of antihypertensive drugs in pregnancy. International Journal of Pharma Sciences and Research, Apr 2014 Vol 5 No 04.

19. Khosravi, S, Dabiran, S, Lotfi M, Asnavandy M. Study of the Prevalence of Hypertension and Complications of Hypertensive Disorders in Pregnancy. Open Journal of Preventive Medicine, 2014, 4, 860-867.

20. Wolde Z, Segni H, Woldie M. Hypertensive Disorders of Pregnancy in Jimma University Specialized Hospital .Ethiop $J$ Health Sci, November 2011, Vol. 21, No 34.

21. Tessema GA., Abebe Tekeste A. Ayele TA. .Preeclampsia and associated factors among pregnant women attending antenatal care. $B M C$ Pregnancy and Childbirth (2015) 15:73 DOI 10.1186/s12884-015-0502-7

22. Seyom E.,Abera M., Tesfaye M., Fentahun N. Maternal and fetal outcome of pregnancy related hypertension. Journal of Ovarian Research (2015) 8:10 DOI 10.1186/s13048-015-0135-5

23. Van Middendorp D, Asbroek A, Yaw Bio F, Edusei A . Rural and urban differences in blood pressure and pregnancy-induced hypertension among pregnant women in Ghana. Globalization and Health 2013, 9:59.

24. Ayele G., Lemma S., Agedew E. Factors Associated with Hypertension during Pregnancy. Quality in Primary Care (2016) 24 (5): 207-213

25. Steven L., Joanne S., Robert L. PhD, Charles J. Lockwood., Beth S. Schachte, Richard B. Gertrud $\mathrm{S}$. Berkowitz. Association between pregnancyinduced hypertension and asthma during pregnancy. Am J Obstet Gynecol. 1992, Volume 168, Number 5.

26. Marie-Josée Martel, Évelyne Rey, Marie-France Beauchesne, Sylvie Perreault, Geneviève Lefebvre, Amélie Forget and Lucie Blais. Use of inhaled corticosteroids during pregnancy and risk of pregnancy induced hypertension: nested casecontrol study, 2005.BMJ, doi:10.1136/bmj.38313.624352.8F 